\title{
Temporal distribution of dengue virus serotypes in Colombian endemic area and dengue incidence. Re-introduction of dengue-3 associated to mild febrile illness and primary infection
}

\author{
Raquel Elvira Ocazionez ${ }^{+}$, Fabián Mauricio Cortés, Luis Angel Villar, Sergio Yebrail Gómez
}

Centro de Investigaciones en Enfermedades Tropicales y Centro de Investigaciones Epidemiológicas, Escuela de Medicina, Universidad Industrial de Santander, Sede Guatiguará Km 2 Autopista Piedecuesta, Santander, Colombia

We have investigated the temporal distribution of dengue (DEN) virus serotypes in the department (state) of Santander, Colombia, in relation to dengue incidence, infection pattern, and severity of disease. Viral isolation was attended on a total of 1452 acute serum samples collected each week from 1998 to 2004. The infection pattern was evaluated in 596 laboratory-positive dengue cases using an IgG ELISA, and PRNT test. The dengue incidence was documented by the local health authority. Predominance of DEN-1 in 1998 and DEN-3 re-introduction and predominance in 2001-2003 coincided with outbreaks. Predominance of DEN-2 in 2000-2001 coincided with more dengue hemorrhagic fever (DHF). DEN-4 was isolated in 2000-2001 and 2004 but was not predominant. There was an annual increase of primary dengue infections (from 13.7 to 81.4\%) that correlated with frequency of $D E N-3(r=0.83 ; P=0.038)$. From the total number of primary dengue infections DEN-3 (81.3\%) was the most frequent serotype. DHF was more frequent in DEN-2 infected patients than in DEN-3 infected patients: $27.5 \mathrm{vs} 10.9 \%$ $(P<0.05)$. DEN-3 viruses belonged to subtype $C$ (restriction site-specific-polymerase chain reaction) like viruses isolated in Sri-Lanka and other countries in the Americas. Our findings show the importance of continuous virological surveillance to identify the risk factors of dengue epidemics and severity.

Key words: dengue serotypes - dengue hemorrhagic fever - dengue-3 - restriction site-specific - polymerase chain reaction

Dengue (DEN) is an acute human disease caused by the dengue viruses, members of the Flaviviridae family, which are transmitted to humans by the bite of infected mosquitoes of the Aedes genus. There are four antigenically related but genetically distinct dengue viruses named DEN-1, DEN-2, DEN-3, and DEN-4 (Heinz et al. 2000). Evidence of the dengue virus in the Americas can be traced back to 1953 when DEN-2 was isolated (Anderson et al. 1956); DEN-1 appeared in 1977 and DEN-4 in 1981 (Gubler 1997, Pinheiro \& Corber 1997). DEN-3 was introduced in 1963 and the last isolation took place in 1977-1978 in Puerto Rico and Colombia (Pinheiro \& Corber 1997). After 17 years of its apparent disappearance in the Americas, DEN-3 re-appeared in 1994 in Nicaragua and Panama and later in Mexico and the Caribbean countries (CDC 1995). In 2000, Brazil and Venezuela reported the re-introduction of this serotype in South America (Nogueira et al. 2001, Uzcategui et al. 2003).

All dengue virus serotypes can cause a spectrum of illness ranging from unapparent or mild febrile illness dengue fever (DF) to the potentially fatal dengue hemorrhagic fever (DHF), and dengue shock syndrome (DSS). Both retrospective and prospective studies have founded strong correlation between disease severity and host im-

Financial support: Colciencias grants 11020-413042/441296, Secretaría de Salud de Santander grant 007-2001

${ }^{+}$Corresponding author: raqueoca@hotmail.com

Received 28 March 2006

Accepted 30 August 2006 mune status; that is, individuals experiencing a second dengue infection with a heterologous serotype are at a greater risk of developing DHF/DSS than individuals experiencing a primary infection. In this setting, it has been demonstrated that there are preexisting antibodies induced by the previous dengue virus infection that bind to the new virus serotype increasing uptake by cells expressing Fc $\gamma$ receptors, such as monocytes and macrophages (Halstead 1998, Kliks 1990). However, DHF and DSS are observed in primary cases, and not all secondary cases develop DHF (Gubler et al. 1978, Burke et al. 1988). Molecular epidemiologic studies provide evidences that differences in virulence between viral strains play a role in determining the overall incidence of DHF in a community with dengue virus transmission (Rico-Hesse et al. 1997).

It has been estimated that over 50 million cases of DF and about 250,000 - 500,000 cases of DHF occur worldwide (Pancharoen et al. 2002). Starting in the 1980 s dengue epidemics in the Americas Region have been characterized by the co-circulation of multiple dengue serotypes in the same area. This rise in hyperendemicity and introduction of dengue viruses of Asian genotypes are believed to be two of the most significant factors contributing to the increase of DHF/DSS. This is because there are more infections by virulent virus genotypes in the context of a secondary infection (Gubler 1997). In Colombia, the first case of dengue was detected in 1971 and an exponential increase in the number of DHF cases has been seen since then. The total number of suspected cases reported was 22,775 in 2000; 55,437 in 2001; 77,996 in 2002 ; 52,588 in 2003, and 27,523 in 2004 (PAHO 20002004). 
Outbreaks of dengue have been occurring in almost all departments (states) of the country while Santander where this study was conducted reports the second largest number of case to the Ministry of Health. All dengue virus serotypes have been detected in Colombia since the 1970, although DEN-3 was not isolated between 1977-2000 (Boschell et al. 1986). Through phylogenetic analyses it has been possible to determine the origin of the dengue serotypes introduced in Colombia. DEN-2 isolated in the 1990s belonged to the Asian genotype III (Rico-Hesse et al. 1997), isolates of DEN-1 in 1985 and 1996 were genotype III (Gonçalvez et al. 2002) and isolates of DEN-4 in 1987 and 2001 belonged to genotype II (Diaz 2004). The genetic subtype distribution of DEN-3 has not been documented.

The epidemiology of dengue infections in Colombia has not been sufficiently studied. The mutual interactions of virus serotypes, pattern of infection, and severity of disease in dengue epidemics is unknown. This report presents the findings about the transmission of dengue viruses in an endemic area in the department of Santander over the period from 1998-2004. Specifically, the temporal changes in relative abundance of serotypes; the reappearance and continued transmission of DEN-3; the association between severity of the disease and dengue serotypes; and the annual changes in the infection pattern (primary vs secondary) in relation to serotype dominant. The findings are analyzed with a view to find correlations between predominance of dengue serotypes and disease incidence and frequency of DHF in Santander.

\section{MATERIALS AND METHODS}

Study site - The current study was conducted in the city of Bucaramanga, capital of the department of Santander, and its metropolitan area which includes three other municipalities. The study covers an area of $165,000 \mathrm{~km}^{2}$ and a population of approximately 804,618 inhabitants (1993) in the Northeastern region of Colombia. It is near the Venezuelan border and at $380 \mathrm{~km}$ from Bogotá the capital of the country. The average temperature in Bucaramanga and its metropolitan area ranges between 22 and $30^{\circ} \mathrm{C}$. The average annual rainfall is $1041 \mathrm{~mm}$ with the bulk of rain falling from Abril to June.

Surveillance of suspected dengue cases - In this study were included febrile cases reported to the dengue surveillance program set up by the local Health Secretariat as follows: patients coming to hospitals and private clinics were clinically examined and a blood samples was taken for routine laboratory test. A standardized dengue case reporting form was completed from each patient to collect clinical and epidemiological data, and a serum specimen was collected for dengue diagnosis. At the Public Health Laboratory of the Health Secretariat serum samples were processed to detect anti-dengue antibody IgM using the UMELISA kit (Instituto Pedro Kouri, La Havana, Cuba). Cases were considered dengue laboratory-positive if an IgM-antibody-capture test was positive. Each week of the month between March 4, 1998 to December 26, 2002 and again from March 4 to December 26, 2004, acute serum to virus isolation were selected from total samples sent to the Public Health Laboratory. Only sera from patients with fever of unknown origin (no respiratory, diarrhoea or other apparent causes for the fever) were included in the study. For each patient the reporting form as well as IgM UMELISA test result were obtained.

Cross-sectional study - Febrile cases without localized sings of infection were enrolled between May 3, 2003 to December 29, 2004. Each day of the week was devoted to enrolling patients at the hospital and private clinics. Patients were invited to participate after giving informed consent and the ethical clearance committee of the local Industrial de Santander University approved the protocol for follow-up. Both physical examination by a physician member of the study group and laboratory tests were performed daily on each patient and treatment was provided according to standard guidelines. A standardized questionnaire was administered to collect demographic and clinical information. An acute sample was collected on the day of admission and a second sample 10-20 days later by appointment at the clinic or by going to the patient home. Sera were sent in to our Laboratory together with demographic and clinical data.

Dengue incidence and severity - Annual laboratorypositive dengue cases and frequency of DHF in Bucaramanga and its metropolitan area during the period of study are shown in Table I. In 1998 and 2001 there was an outbreak. The severity of disease in patients included in this study was established for dengue virologically confirmed cases according to the WHO guidelines (WHO 1980). A study physician checked the reporting form or hospitalization records from patients reported to local dengue surveillance program. DHF was defined as fever with hemorrhagic manifestations, thrombocytopenia (platelet count $\leq 100,000 / \mathrm{mm}^{3}$ ), and signs of plasma leakage (hemoconcentration, hypoproteinaemia or pleural effusion).

Virus isolation - Acute sera were processed for virus isolation in Ae. albopictus cells culture (clone C6/36) as previously described (Ocazionez et al. 2005). Briefly, culture tubes inoculated with $100 \mu 1$ of serum (1:30) were centrifuged for $30 \mathrm{~min}$ at $1000 \times \mathrm{g}$ at $28^{\circ} \mathrm{C}, 1 \mathrm{ml}$ of culture medium was added to each tube and the cells were kept at $32^{\circ} \mathrm{C}$ for 12 days. DV were detected by direct fluorescent

\section{TABLE I}

Dengue in suspected cases laboratory-investigated in according to year. Bucaramanga and metropolitan area, Santander, Colombia

\begin{tabular}{lrcc}
\hline Year & Cases & Dengue $^{a}$ & ${\text { DHF }(\%)^{b}}^{b}$ \\
\hline 1998 & 2399 & 1937 & 3.7 \\
1999 & 686 & 355 & 0.5 \\
2000 & 1412 & 509 & 8.6 \\
2001 & 3373 & 2683 & 7.4 \\
2002 & 2788 & 2207 & 4.7 \\
2003 & 2509 & 1852 & 4.3 \\
2004 & 881 & 364 & 3.5 \\
\hline
\end{tabular}

$a$ : IgM-antibody-capture test ELISA positive (Public Health Laboratory of the local Health Secretariat, Bucaramanga); DHF: dengue haemorragic fever; $b$ : Álvarez et al. 2004. 
antibody test using a polyclonal antibody (M29341) (CDC, Puerto Rico). Positive samples were retested by indirect fluorescent antibody test on virus-infected cell for identification of serotype using specific monoclonal antibodies (CDC, Puerto Rico).

Restriction site-specific-polymerase chain reaction (RSS-PCR) - For molecular subtyping isolates of DEN3 a modification of the protocol described by Harris et al. (1999) PCR-based was followed. Viruses were propagated in $\mathrm{C} 6 / 36$ cells culture and the supernatants submitted to RNA extraction by Trizol ${ }^{\circledR}$ (GIBCO BRL, Grand Island, NY). Reverse transcription was conducted at $42^{\circ} \mathrm{C}$ using two anti-sense primers (RSS7-8), followed by amplification cycles using four primers (RSS5-8). The RSS-PCR patterns were interpreted as previously described (Harris et al. 1999) Dengue virus strains representing the DEN-3 subtypes A, B, and C (CDC, Fort Collins, CO) were included.

IgM ELISA - Serum samples collected from patients enrolled in the cross-sectional study were tested by IgM capture ELISA as previously described (Ocazionez et al. 2005). Briefly, serum diluted 1:40 was added to 96-well coated with goat anti-human IgM antibody followed by a dengue antigen (CDC, Puerto Rico) and horse-radish peroxidase (HRP)-conjugate anti-flavivirus antibody (CDC, Puerto Rico). Specimens were considered positive if the absorbance value $\left(\mathrm{OD}_{405}\right)$ was 2.5 the mean of the negative controls. Cases were considered dengue laboratorypositive if an IgM-antibody-capture test was positive.

IgG ELISA - IgG antibodies anti-dengue viruses were measured in serum samples collected 0-4 days after onset of symptoms from dengue laboratory-positive cases. The protocol for IgG ELISA was the same used for IgM ELISA. Primary or secondary infection status was determined by the absence or presence of $\operatorname{IgG}$ antibody in an acute phase sample.

Plaque reduction neutralization test - Sera tested by IgG ELISA were tested by PRNT test using a modification of the method described by Vorndam and Beltran (2002). Briefly, heat-inactivated sera were diluted 1:320 in media (MEM), were mixed with the virus (40-60 pfu/well) and incubated for $2 \mathrm{~h}$ at room temperature. The mixture was inoculated onto Vero cells in 24-well plates, the plates incubated at $37^{\circ} \mathrm{C}\left(5 \% \mathrm{CO}_{2}\right)$ for five days and then stained with $3.2 \%$ neutral red solution. A $85 \%$ reduction in plaque count in at least two dengue serotypes was used as presence of anti-dengue neutralizing antibodies. Primary or secondary infection status was defined as monotypic or heterotypic neutralizing antibody response in an acute phase sample. The results of PRNT and IgG ELISA tests correlated $100 \%$.

Statistical analysis - Annual frequency of primary and secondary dengue infectious and isolations of DEN-2 and DEN-3 were compared by linear regression analyses. Frequency of DHF in DEN-2 and DEN-3 infected patients was compared using $\chi^{2}$ test. Mean of ages (years) in dengue virologically confirmed cases were compared by two-factor analysis of variance (ANOVA). Analyses were done using the SPSS for Windows software version 13.0 (SPSS, Chicago). $P<0.05$ was considered significant.

\section{RESULTS}

Dengue serotypes and dengue incidence - All dengue virus serotypes were isolated over the period of study. DEN-3 (58.2\%) was the serotype more frequent followed by DEN-2 (22.8\%), DEN-1 (11\%), and DEN-4 (7.8\%) (Table II). Changes in annual predominance of serotype coincided with changes in the dengue incidence reported by the local Health Secretariat. In 1998, DEN-1 (55.5\%) dominated followed by DEN-2 (44.5\%) and the others serotypes were not isolated. The first outbreak occurred this year. In the following two years (1999-2000), DEN-2 $(64.2 \%)$ was the dominant serotype followed by DEN-1 (21.4\%) and DEN-4 (14.2\%), and low dengue activity was reported in this period. In 2001, when the second outbreak happened, DEN-3 re-appearance after 23 years, and together with DEN-2 was the most prevalent $(36$ and $40 \%$, respectively), followed by DEN-4 (20\%) and DEN-1 (4\%). In 2002-2003, DEN-3 (94.5\%) became the most prevalent, followed by DEN-2 (3.8\%) and DEN-1 (1.9\%) and dengue activity was still high. In 2004, DEN-3 (75\%) continued as the dominant serotype following by DEN-4 (14.2\%), DEN-2 (9.5\%), and DEN-1 (4.7\%) but this year the dengue incidence decreased as expected for an interepidemic period. On the other hand, DEN-2 dominance in 20002001 ( 17 out of 35 isolates; $48.5 \%$ ) coincided with the period of highest frequency of DHF (242 from 3192 cases; $7.6 \%$ ). In contrast, DEN-3 dominance in 2003-2004 (52 from 59 isolates; $88.1 \%$ ) coincided with a decrease in the frequency of DHF cases (197 from 4423 cases; 4.4\%) compared with 2000-2001.

Infection pattern and dengue serotype dominance The infection pattern was evaluated in a total of 596 laboratory-positive dengue. The mean age (years) of patients enrolled in 1998, 2000, 2001, 2003, and 2004 was $25 \pm 19$; $22 \pm 18 ; 24 \pm 17 ; 24 \pm 18 ; 27 \pm 17 ; 26 \pm 17$, respectively. By using IgG-ELISA and PRNT test, the infection in 262 $(43.9 \%)$ cases was characterized as primary and in 334 $(56 \%)$ cases as secondary. The proportion of cases with primary dengue increased over the study period from $13.7 \%$ in 1998 to a peak of $81.4 \%$ in $2004(\mathrm{r}=0.93 ; P=$

\section{TABLE II}

Annual distribution of dengue virus serotypes isolated in Bucaramanga and metropolitan area, Santander, Colombia

\begin{tabular}{lrrrcrc}
\hline & & & \multicolumn{4}{c}{ Serotypes: count } \\
\cline { 4 - 7 } Year & Sera & Virus & DEN-1 & DEN-2 & DEN-3 & DEN-4 \\
\hline $1998^{a}$ & 108 & 14 & 8 & 6 & 0 & 0 \\
$1999^{a}$ & 112 & 4 & 2 & 2 & 0 & 0 \\
2000 & 170 & 10 & 1 & 7 & 0 & 2 \\
$2001^{a}$ & 212 & 25 & 1 & 10 & 9 & 5 \\
$2002^{a}$ & 186 & 15 & 1 & 1 & 13 & 0 \\
2003 & 263 & 38 & 0 & 1 & 37 & 0 \\
2004 & 401 & 21 & 1 & 2 & 15 & 3 \\
\hline Total & 1452 & 127 & 14 & 29 & 74 & 10
\end{tabular}

a: outbreak (Álvarez et al. 2004). 
0.006 , by linear regression test) (Table III). There was correlation between the annual increase of primary infections and frequency of DEN-3 isolates $(\mathrm{r}=0.83 ; P=$ 0.038 , linear regression test), but not between the annual decrease of secondary infections and frequency of DEN2 isolates $(\mathrm{r}=0.82 ; P=0.061$, linear regression test). There were more secondary infections in the year of first outbreak (1998; DEN-1 dominant) than in the year of second outbreak (2001; DEN-2 and DEN-3 dominants): 86.3 vs $73.5 \%$, but these differences were not significant $\left(P>0.05, \chi^{2}\right.$ test $)$. From the total $(\mathrm{n}=75)$ primary dengue patients with virus isolated, DEN-3 $(81.3 \%)$ was the most frequent serotype followed by DEN-1 (9.3\%), DEN-2 (8\%), and DEN-4 (1.3\%). In contrast, DEN-2 (45.6\%) was more frequent than others serotypes in patients with secondary dengue $(n=46)$.

Dengue serotypes and dengue disease severity - The relationship between isolated virus dengue serotype and clinical severity was examined according to WHO guidelines. In DEN-2 infected patients DHF was more frequent than in DEN-3 infected patients: 27.5 vs $10.9 \%(P<0.05$, $\chi^{2}$ test). From the DHF/DEN-2 patients, four ended fatally and three of them had secondary infection. The primary case was a child $<6$ months of age, a period of life where the presence of maternal antibodies, if the mother had suffered dengue, could have resulted in an enhanced infection. Out of eight DHF/DEN-3 patients six were primary infection of which one was grade-I, two grade II and three grade-III (Table IV). In general, the DEN-3 in-

\section{TABLE III}

Infection pattern in laboratory-positive dengue cases in according to year. Bucaramanga and metropolitan area, Santander, Colombia

\begin{tabular}{lccc}
\hline Year $^{a}$ & Cases & $\begin{array}{c}\text { Primary } \\
\text { no. (\%) }\end{array}$ & $\begin{array}{c}\text { Secondary } \\
\text { no. }(\%)\end{array}$ \\
\hline 1998 & 80 & $11(13.7)$ & $69(86.3)$ \\
2000 & 84 & $11(25.0)$ & $63(75.0)$ \\
2001 & 128 & $34(26.5)$ & $94(73.5)^{c}$ \\
2002 & 106 & $48(45.2)$ & $58(54.8)$ \\
2003 & 80 & $62(77.5)$ & $18(22.5)$ \\
2004 & 118 & $96(81.4)$ & $22(18.6)$ \\
\hline
\end{tabular}

$a: 1998$ and 2001 outbreak (Álvarez et al. 2004), 2001-2004 DEN-3 dominant; $b$ : increase over time $(P=0.006$, linear regression); $c: P>0.05$ compared with secondary infection in 1998. fections were characterized by low disease severity, count platelet $<100,000 / \mathrm{mm}^{3}$, petechiae or another type of hemorragies, retro-orbital pain, and vomiting were infrequent. In DEN-1 infected patients $(\mathrm{n}=11)$, four developed DHF (two secondary infection), and all DEN-4 infections $(\mathrm{n}=8)$ were of DF. The mean age (years) of DEN-1 $(22.1 \pm 28.1), \mathrm{DEN}-2(25.1 \pm 18.3)$, DEN-3 (26.0 \pm 16.1$)$, and DEN-4 (21.1 \pm 4.7$)$ cases did not show significant difference $(P>0.05$, ANOVA test $)$.

$D E N-3$ subtype - For virus subtype identification of DEN-3 isolates, 33 strains were analyzed by RSS-PCR (Figure). All viruses could be classified as type $\mathrm{C}$, since fragments of 655 and $527 \mathrm{pb}$, and $180 \mathrm{pb}$ in some strains, were amplified. This pattern was similar to DEN-3 viruses isolated in Sri-Lanka (1990), Puerto Rico (2000), and Honduras (1995), but different to isolates from Philipines (H87; 1956) and Samoa (1995). RSS-PCR type-C is consistent with the genotype III previously described by sequencing (Harris et al. 1999).

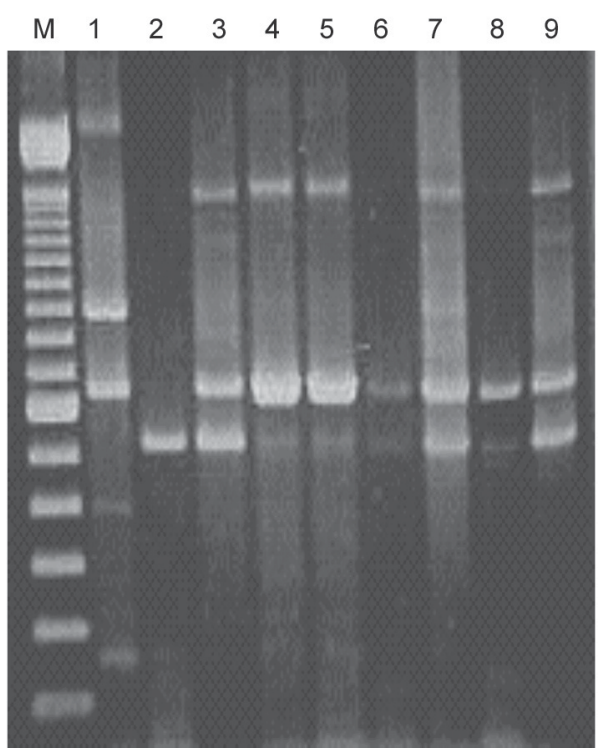

Restriction site specific-polymerase chain reaction (RSS-PCR) patterns of DEN-3 viruses. Lanes - M: 100-basepair (bp) ladder (GibcoBRL); 1: RSS-PCR type A (Philippines 1956/H87); 2: RSS-PCR type B (Samoa 1995); 3: RSS-PCR type C (Sri Lanka 1990); 4: RSS-PCR type C (DEN-3 Puerto Rico 2000); 5: RSS-PCR type C DEN-3 (Honduras 1995); 6-9: Colombian DEN-3 strains (20012004).

TABLE IV

Comparison of dengue severity and infection pattern in DEN-2 and DEN-3 infected patients. Bucaramanga and metropolitan area, Santander, Colombia (1998-2004)

\begin{tabular}{|c|c|c|c|c|c|c|c|c|c|c|}
\hline \multirow[b]{2}{*}{ Serotype } & \multirow[b]{2}{*}{ No. } & \multicolumn{3}{|c|}{ DF } & \multicolumn{3}{|c|}{ DHF } & \multicolumn{3}{|c|}{ Fatal } \\
\hline & & $1 \mathrm{st}$ & 2nd & $\%$ & $1 \mathrm{st}$ & 2nd & $\%$ & $1 \mathrm{st}$ & 2nd & $\%$ \\
\hline DEN-2 & 29 & 10 & 7 & 58.6 & 0 & 8 & $27.5^{a}$ & 1 & 3 & 13.7 \\
\hline DEN-3 & 74 & 56 & 10 & 89.1 & $6^{b}$ & 2 & 10.9 & 0 & 0 & 0 \\
\hline
\end{tabular}

$a: \mathrm{p}<0.05, \chi^{2} ; b:$ three were grade III. 


\section{DISCUSSION}

The reappearance of DEN-3 virus in Colombia was detected by the first time in the department of Santander in 2001. The first virus strain was isolated from a patient who had traveled to the city of Cucuta, located $30 \mathrm{~km}$ from the Venezuelan border and $180 \mathrm{~km}$ from Bucaramanga, ten days before onset of symptoms. Dengue outbreaks have been occurring in this city and isolation of DEN-3 was reported by the Colombian National Institute of Health in 2002 (Gomez et al. 2002). Four years after its introduction in Colombia DEN-3 was detected in the Northern, Southern, and Southeastern regions of the country causing outbreaks (Ministerio de Salud y Protección Social 2002, Bernal et al. 2002, Ospina 2004). It is difficult to determine the precise route of importation of DEN-3 into Colombia because data are limited. However, if we take together the virus reappearance in Venezuela the year before its re-introduction in the Santander area, and the history of the patient on whom the first strain was isolated, the city of Cúcuta could easily have been be the entrance point of DEN-3 arriving from Venezuela. Therefore, the reappearance of this serotype in Colombia is more likely the result of the spread of a virus circulating in Venezuela than of direct importation from Central Americas countries. This assumption could be supported by the finding that DEN-3 has been circulating in Panama since 1994, yet the virus was detected in the Colombian region near to Panama border only after its introduction in Santander (Ospina 2004).

The re-introduction of DEN-3 into Colombia was expected to cause an outbreak and increase the number of severe cases by several reasons: (a) this serotype had not been detected in the country during the last 23 years and therefore many more individuals were totally susceptible to infection; (b) reappearance of the virus in Central American countries caused epidemics (CDC 1995, Pinhero \& Corber 1997, Rigau et al 2002, Peláez et al 2004); (c) the DEN-3 strain currently circulating in Latin American caused DHF epidemics in Asian countries in the 1980s (Lanciotti et al 1994, Messer et al 2003); and (d) more dengue infections of the secondary type would occur on account of hyperendemicity due to others serotypes.

Epidemiological studies have been suggested that a dengue virus introduction into an area of a susceptible human population would soon or late produce an epidemic, depending on the competition of other serotypes, herd immunity in the population, characteristics of introduced virus strain and mosquito densities (Fine 1993, Focks et al. 1995). In Brazil, the arrival of DEN-3 in 2000 coincided with an outbreak due to DEN-1 and DEN-2, and was followed by an epidemic associated with DEN-3 two years later (De Simone et al. 2004, Passos et al. 2004, Nogueira et al. 2005). In Puerto Rico, the re-appearance of DEN-3 in 1998 was detected during a prolonged epidemic caused by DEN-1 and DEN-4 concealing the DEN-3 epidemic, yet a low number of cases caused by this serotype was reported in the first two years of its reintroduction (Rigau et al. 2002). In contrast in Santander despite continuous virological surveillance DEN-3 was detected during but not before the 2001 outbreak and after its introduction the virus was dominant and technically produced an extended epidemic quickly. During the two years following the re-introduction of DEN-3 in 2001, 4046 more laboratory-positive dengue cases were detected than the two years before (Table I). Herd immunity could be an additional factor to partially explain why the early and extended time of the DEN-3 epidemic in Santander. Our findings that the yearly proportion of primary dengue cases increased after re-introduction of the virus and that it was correlated to frequency of isolates suggest a low herd immunity to DEN-3 in the population presumably favoring its dominance.

Previous phylogenetic studies revealed that DEN-3 viruses isolated in the Americas during the 1970s belonged to genotype IV, but the currently circulating strain is genetically different and belongs to genotype III (Lanciotti et al. 1994). Our RSS-PCR results indicated that DEN-3 strains isolated in Santander belonged to subtype C like viruses grouped in the genotype III isolated in Puerto Rico and Honduras (Figure) and viruses introduced in Brazil and Venezuela in 2000 (Nogueira et al. 2001, Uzcategui et al. 2003). This genetic variant has been associated with DHF/DSS epidemic in India and Africa (Lanciotti et al 1994, Messer et al 2003), but its introduction into Central American countries caused a small number of DHF/DSS. In Panama (1994) produced a classic DF outbreak while in Nicaragua (1994), and Mexico (1995) was associated with an increased number of cases but DEN-1 and DEN-2 produced the majority of severe cases (Briceño et al. 1996). Moreover, in Nicaragua the 1998 outbreak was associated with DEN-3 re-emergence but the majority of DHF cases were DEN-2 infections (Harris et al. 2000). The same was seen in Venezuela where a great number of dengue cases occurred after re-introduction of DEN-3 in 2000 but more frequently of DF (Uzategui et al. 2003). Santander was not different, the majority of DEN-3 infected patients suffered DF and the frequency of DHF diminished during the dominance of the virus as compared with the period when DEN-2 dominated. However, in Brazil the predominance of DEN-3 two years after its introduction for the first time in 2000 was associated with severe epidemic in terms of the severity of clinical manifestations, and the number of deaths caused by this serotype (Nogueira et al. 2005).

The low association between DHF and DEN-3 infection observed in Santander was not something expected as others dengue serotypes have been co-circulating continuously since the 1990s. Under such circumstances, one could assume that dengue secondary infection would be more frequent and would probably increase the likelihood of DHF/DSS. However, this was not the case considering that out of DEN-3 infections $81.3 \%$ were primary, and this pattern of infection increased when the virus became predominant (Table III). These findings suggest that either the DEN-3 strains circulating currently in Santander are more pathogenic among individuals without immune priming from prior dengue infection, or that a higher proportion of individuals have cross-reactive immunity due to one of the others dengue serotypes that would protect of severe DEN-3 infection. In this study, 
the infected DEN-3 patients with dengue more severe (DHF grade III) were primary infection, and in Brazil 20 out of 29 fatal cases occurred during DEN-3 epidemic were primary infection (Nogueira et al. 2005). On the other hand, there was more secondary than primary dengue infections during DEN-3 outbreak in Nicaragua in 1998 when the virus caused a small number of DHF cases (Harris et al. 2000), and in Brazil 44.3\% of nonfatal cases of confirmed DEN-3 infection were classified as secondary infection (Nogueira et al. 2005). Cross-reactive humoral immune response seems to be beneficial in symptomatic secondary DEN-3 infections (Endy et al. 2004). Another possible explanation for low severity associated to DEN-3 in Santander is that some strains might have lost virulence as compared with the Indian strain. However, differences present among the $\mathrm{E}$ gene and the untranslated region (UTR) sequences of viruses isolated from Brazilian and Venezuelan patients suffering from DF, DHF or DHF/DSS can not be related to disease severity (Uzategui et al. 2003, Miagostovich et al. 2006).

Of the four serotypes, DEN-2 is the most frequently isolated from dengue severe cases. The marked increase in the number of DHF/DSS cases seen in Latin American countries after 1981 has been largely attributed to introduction of a novel strain of DEN-2 classified as subtype III and also termed the Asian-American subtype (RicoHesse et al. 1997). DEN-2 strains isolated in Colombia in the 1990s have been grouped into this subtype (RicoHesse et al. 1997). We analyzed by RSS-PCR DEN-2 viruses isolated in Santander resulting subtype A like viruses grouped into subtype III and isolated in other Latin American countries (Gómez et al. 2001). This serotype was the most frequently isolated in DHF patients identified in this study and predominated in 2000-2001 when more DHF cases were reported by the local Health Secretariat. It is suggested that individuals with specific neutralizing antibodies anti-DEN-1 due to prior infection would be at a greater risk of severe disease suffering DEN2 secondary infection (Kouri et al. 1989, Endy et al. 2004). In this study, antibodies anti-DEN-1 were detected in eight (leading to three fatalities) out of ten DHF patients with DEN-2 secondary infection using PRNT test (date not shown). If we consider that in Santander DEN-1 dominated two years before predominance of DEN-2 and that the second serotype has been permanently isolated, we might assume that there is a significant proportion of individuals with preexisting neutralizing antibodies directed against DEN-1 that could be infected with DEN-2 and developed DHF. Thus, an increase of DHF in Santander might be expected for the coming years.

This longitudinal serotype-specific study of dengue is unique in Colombia. Based on our results we have demonstrated that at least three dengue serotypes have cocirculated in Bucaramanga and the metropolitan area in the last seven years. Our results support the concept that each serotype should be considered as a separate virus with its own unique viral characteristics and host factors interactions with the potential to produce moderate or severe disease. Therefore, continued virological surveillance for early detection of serotype-specific emergence or re-introduction becomes necessary in endemic areas in order to predict severe dengue years.

\section{ACKNOWLEDGEMENTS}

To local Health Secretariat of Santander, its epidemiological group especially to Dr Alba Nury Correa and Dr Leonor de Mendieta, Chief of Public Health Laboratory. To Dr Vancen Vorndam (CDC, Puerto Rico) for kindly providing dengue viruses strains and antibodies, and to Dr Fredi Diaz and Dr Ruth Martínez for collecting information on hospitalized dengue cases.

\section{REFERENCES}

Álvarez A, Martínez H, Millán S, López L 2004. Diagnóstico de la Situación de Salud en Santander, 2nd ed., Secretaría de Salud de Santander, Santander, 56 pp.

Anderson C, Downs W, Hill A 1956. Isolation of dengue virus from a human being in Trinidad. Science 124: 224-225.

Boschell J, Groot H, Gacharna M, Márquez G, González M, Gaitán MO, Berlie CH, Martínez M 1986. Dengue en Colombia. Biomédica 6: 101-102.

Briceño-García B, Gómez-Dantés H, Argot-Ramirez E, Montesano R, Vázquez-Martínez AL, Ibañez-Bernal S, Madrigal-Ayal G, Ruiz-Matus C, Flisser A, Tapia-Coyner R 1996. Potential risk for dengue hemorrhagic fever: the Isolation of serotype Dengue-3 in Mexico. Emerg Infect Dis 2: 133-135.

Burke DS, Nisalak A, Johnson DE, Scott RM 1988. A prospective study of dengue infections in Bangkok. Am J Trop Med Hyg 38: 172-180.

CDC-Centers for Disease Control 1995. Dengue type 3 infection-Nicaragua and Panama, October-November,1994. MMWR 44: 21-24.

De Simone TS, Nogueira RM, Araújo ES, Guimarães FR, Santos FB, Schatzmayr HG, Souza RV, Texeira Filho G, Miagostovich MP 2004. Dengue virus surveillance: the cocirculation of DENV-1, DENV-2 and DENV-3 in the state of Rio de Janeiro, Brazil. Trans R Soc Trop Med Hyg 98: 553-562.

Diaz JF 2004. Epidemiología molecular del dengue en las Americas. Memorias del primer simposio nacional de Virología, Universidad de Antioquia, Medellín, Colombia. Iatreia 17: $7 \mathrm{pp}$.

Endy TP, Nisalak A, Chunsuttitwat S, Vaugh DW, Green S, Ennis FA, Rothman AL, Libraty DH 2004. Relationship of preexisting dengue virus (DV) neutralizing antibodies levels to viremia and severity desease in a prospective cohort study of DV infection in Thailand. J Infect Dis 189: 9901000 .

Fine P 1993. Herd immunity: history, theory, practice. Epidemiol Rev 15: 265-301.

Focks DA, Daniels E, Haile DG, Keesling JE 1995. A simulation model of the epidemiology of urban dengue fever. Literature analysis, model development, preliminary validation, and samples of simulation results. Am J Trop Med Hyg 53: 489-506.

Gomez SY, Méndez J, de Calvache D, Quintero J, Velandia M 2002. Circulación de virus dengue serotipo 3 en Colombia, 2002. II Congreso Nacional Investigación y Salud. Biomédica 22: $147 \mathrm{pp}$. 
Gómez SY, Ocazionez RE, Cortés FM 2003. Caracterización genética de virus dengue que han circulado en el Departamento de Santander mediante amplificación simultánea de sitios para enzimas de restricción. Resúmenes del Congreso de la Asociación Colombiana de Parasitología y Medicina Tropical, 2003. Biomédica 23: 122 pp.

Gonçalvez A, Escalante A, Pujol FH, Ludert J, Tovar D, Salas R, Lipandri F 2002. Diversity an evolution of the envelope gene of dengue virus type 1. Virology 303: 110-119.

Gubler DJ 1997. Dengue and dengue hemorrhagic fever: its history and resurgence as a global public health problem. In Gubler DJ, Kuno G (eds), Dengue and Dengue Hemorrhagic Fever, CAB International, Wallingford, p. 1-22.

Gubler DJ, Reed D, Rosen L, Hitchcock J 1978. Epidemiologic, clinical, and virologic observations on dengue in the Kingdom of Tonga. Am J Trop Med Hyg 27: 581-589.

Halstead SB 1988. Pathogenesis of dengue: challenges to molecular biology. Science 239: 476-481.

Harris E, Sandoval E, Xet-Mull AM, Johnson M, Riley LW 1999. Rapid subtyping of dengue viruses by restriction site-specific (RSS)-PCR. Virology 253: 86-95.

Harris E, Videa E, Perez L, Sandoval E, Tellez Y, Perez M, Cuadra K, Rocha J, Idiaquez W, Alonso R, Delgado M, Campo L, Acevedo F, Gonzalez A, Amador J, Balmaseda A 2000. Clinical, epidemiologic, and virologic features of dengue in the 1998 epidemic in Nicaragua. Am J Trop Med Hyg 2: 5-11.

Heinz FX, Collett MS, Purcell RH, Gould EA, Howard CR, Houghton M, Moormann R, Rice C, Thiel H 2000. Family Flaviviridae. In Virus Taxonomy. Seventh International Committee for the Taxonomy of Virases, Academic Press, San Diego, p. 859-878

Kliks S 1990. Antibody-enhanced infection of monocytes as the pathogenetic mechanism for severe dengue illness. AIDS Res Hum Retroviruses 6: 993-998.

Kouri GP, Guzmán MG, Bravo JR, Triana C 1989. Dengue haemorrhagic fever/dengue shock syndrome: lessons from the Cuban epidemic, 1981. Bull WHO 67:375-380.

Lanciotti RS, Lewis JL, Gubler DJ, Trent DW 1994. Molecular evolution and epidemiology of dengue-3 viruses. J Gen Virol 75: 65-75.

Messer WB, Gubler DJ, Harris E, Sivananthan K, de Silva AM 2003. Emergence and global spread of a dengue serotype 3, subtype III virus. Emerg Infect Dis 9: 800-809.

Miagostovich MP, dos Santos FB, Fumian TM, Guimarães FR, da Costa EV, Tavares FN, Tavares FN, Coelho JO, No-gueira RM 2006. Complete genetic characterization of a Brazilian dengue virus type 3 strain isolated from a fatal outcome. Mem Inst Oswaldo Cruz 101: 307-313.

Ministerio de Salud y Protección Social. Instituto Nacional de Salud. Vigilancia virológica del dengue en Colombia 2002. URL./ http://www.ins.gov.co/pdf_investiga/v_dengue

Nogueira RM, Miagostovich MP, Filippis AMB, Pereira MAS, Schatzmayr HG 2001. Dengue virus type 3 in Rio de Janeiro,
Brazil. Mem Inst Oswaldo Cruz 96: 925-926.

Nogueira RM, Schatzmayr HG, Filippis AMB, Santos FV, Cunha RV, Coehlo JO, Souza LJ, Guimarães FR, Araújo ESM, De Simone TS, Baran M, Texeira G, Miagostovich MP 2005. Dengue virus type 3, Brazil, 2002. Emerg Infect Dis 11: 1376-1381.

Ocazionez R, Cortés F, Villar LA 2005. Vigilancia del dengue basada en el laboratorio: diferencias en el número de casos y virus aislados según la recolección del suero y la prueba serológica. Colombia Médica 36: 65-72.

Ospina MC 2004. Vigilancia epidemiológica del dengue en Antioquia. Memorias del 1er. Simposio Nacional de Virología, Medellín 2004. Iatreia 17: 9 pp.

PAHO 2000-2004. Number of reported cases of dengue \& dengue hemorrhagic fever (DHF). Region of the Americas (by country and subregion). URL./ http://www.paho.org/ english/ad/dpc/cd/dengue

Pancharoen C, Kulwichit W, Tantawichien T, Thysiakorn U, Thisyakorn C 2002. Dengue infection: a global concern. J Med Assoc Thai I: S25-33.

Passos M, Santos L, Pereira M, Casali CG, Fortes B, Ortiz Valencia L, Alexandre J, Medronho R 2004. Clinical differences observed in patients with dengue caused by different serotypes in the epidemic of 2001/2002, occurred in Rio de Janeiro. Rev Soc Bras Med Trop 37: 293-295.

Peláez O, Guzmán MG, Kouri G, Pérez R, San Martín JL, Vásquez S, Rosario D,Mora R, Quintana I, Bisset J, Cancio R, Mesa AM, Castro O, González D, AvilaLC, Rodriguez R, Alvarez M, Pelegrino JL, Bernardo L, Prado I 2004. Dengue 3 Epidemic, Havana, 2001. Emerg Infect Dis 10: 719-722.

Pinheiro F, Corber S 1997. Global situation of dengue and dengue haemorrhagic fever, and its emergence in the Americas. World Health Stat Q 50: 161-169.

Rico-Hesse R, Harrison L, Salas R, Tovar D, Nisalak A, Ramos C, Boshell J, de Mesa M, Nogueira R, Travassos da Rosa A 1997. Origins of dengue type 2 viruses associated with increased pathogenicity in the Americas. Virology 230: 244-251.

Rigau J, Ayala A, García E, Hudson S, Vordam V, Reiter P, Cano M, Clark G 2002. The reappearance of dengue-3 and a subsequent dengue-4 and dengue- 1 epidemic in Puerto Rico. Am J Trop Med Hyg 67: 355-362.

Uzcategui N, Comach G, Camacho D, Salcedo M, Cabello de Quintana M, Jimenez M, Sierra G, Cuello de Uzcategui R, James WS, Turner S, Holmes E, Gould E 2003. Molecular epidemiology of dengue virus type 3 in Venezuela. J Gen Virology 84: 1569-1575.

Vorndam V, Beltran M 2002. Enzyme-linked immunosorbent assay-format microneutralization test for dengue viruses. Am J Trop Med Hyg 66: 208-212.

WHO 1980. Guide for diagnosis, treatment and control of dengue hemorrhagic fever. Technical Advisory Committee on Dengue hemorrhagic fever for the South East Asian and Western Pacific regions, Geneva. 